\title{
Regional differences in use of endoscopic ultrasonography in Ontario: a population-based retrospective cohort study
}

\author{
Paul D. James MD MSc, Mae Hegagi BSc, Lilia Antonova BSc PhD, Jill Tinmouth MD PhD, \\ Steven J. Heitman MD MSc, Carmine Simone MD, Elaine Yeung MD, Elaine Yong MD MSc
}

\section{Abstract}

Background: Endoscopic ultrasonography is a safe and accurate modality for evaluating and managing hepatobiliary and gastrointestinal conditions (malignant and nonmalignant); its use is increasing. The aim of this study was to describe regional trends in the use of endoscopic ultrasonography in Ontario.

Methods: We conducted a population-based retrospective cohort study using health administrative databases. We identified all patients who underwent an endoscopic ultrasound procedure in Ontario from 2003 to 2011 using physician billing data. Patient, physician and institution characteristics were examined. The primary outcome was use of endoscopic ultrasonography.

Results: We identified 9076 endoscopic ultrasound procedures performed in 8001 patients (3858 women [48.2\%]; median patient age at first procedure 59 years). A total of 3066 procedures (33.8\%) involved fine-needle aspiration. Use of endoscopic ultrasonography increased 17-fold over the study period. In 2011, people living in the health region with the highest rate of use of endoscopic ultrasonography were more than 4 times more likely to undergo the procedure than people living in the health region with the lowest rate of use (standardized rate $61.6 \mathrm{v}$. 12.9 per 100 000). About 7 in 10 endoscopic ultrasound procedures were performed in an academic institution or regional cancer centre. All 17 endoscopists performing endoscopic ultrasonography during the study period practised in urban areas.

Interpretation: Although the use of endoscopic ultrasonography increased over time in Ontario, there were marked regional differences in use. Provincial needs- and evidence-based initiatives may be needed to narrow the regional gaps in provision of endoscopic ultrasound services in the province.

\begin{abstract}
$\checkmark$ ince its introduction, in the 1980s, endoscopic ultrasonography has been shown to be a safe and effective diagnostic and therapeutic tool for the evaluation of hepatobiliary and gastrointestinal conditions. ${ }^{1,2}$ Endoscopic ultrasonography allows for high-resolution imaging of the gastrointestinal tract and adjacent structures, is minimally invasive and has a low risk of complications. ${ }^{3}$ It is often used as a complementary procedure to computed tomography and magnetic resonance imaging for the evaluation of suspected malignant disorders, as its high-resolution imaging enables it to detect small lesions that would be difficult to discriminate with either of these 2 other imaging modalities. ${ }^{3}$ Fine-needle aspiration guided by endoscopic ultrasonography is routinely used to obtain histological samples of pancreatic lesions, submucosal tumours and lymph nodes. ${ }^{4-8}$ In concert with the rising burden of gastrointestinal and hepatobiliary conditions in Canada and elsewhere, ${ }^{9-12}$ the applications of interventional endoscopic ultrasonography continue to increase and currently include drainage of pancreatic fluid collection, biliary
\end{abstract}

drainage, celiac plexus nerve blockade and radiologic placement of fiducial markers. ${ }^{13}$ Multiple investigations have shown that endoscopic ultrasound evaluation can alter patient management in up to $74 \%$ of cases, including those of gallstone disease or pancreatitis as well as esophageal, pancreatic, stomach and rectal cancers. For most patients, endoscopic ultrasound evaluation leads to less invasive and costly treatments. ${ }^{13-16}$

Single- and multicentre studies have shown an increase in the application of endoscopic ultrasonography over time; ${ }^{17,18}$ however, these findings may not be generalizable to broader populations. Furthermore, little is known about regional

\section{Competing interests: None declared.}

This article has been peer reviewed.

Correspondence to: Paul James, pjames@toh.on.ca

CMAJ Open 2017. DOI:10.9778/cmajo.20160153 
trends in use. The aim of this study was to describe regional trends in the use of endoscopic ultrasonography in Ontario. Our principal objective was to determine whether regional variation in the use of this modality exists in Ontario and, if so, whether there are patient, provider or institutional factors that may be contributing to regional differences.

\section{Methods}

\section{Study design and setting}

This was a retrospective cohort study set in Ontario using health administrative data on endoscopic ultrasound procedures performed between Jan. 1, 2003 and Dec. 31, 2011. We selected this time window based on the fact that endoscopic ultrasonography codes were introduced in Ontario in 2001 and allowing for a 2-year lead-in period for data capture. At the time of data collection, 2011 was the most recent year with complete and accurate data available.

The study was conducted at the Institute for Clinical Evaluative Sciences, Toronto, which houses the health records of all 13.5 million residents of Ontario. Health administrative databases within the institute are linked by an encrypted version of each resident's provincial health number.

\section{Data sources}

Institute for Clinical Evaluative Sciences data sources included the Ontario Cancer Registry, which captures incident cancer cases diagnosed in Ontario since 1964. Ontario Cancer Registry diagnostic codes for malignant conditions have been validated and have been shown to be over $95 \%$ complete and over $90 \%$ accurate. ${ }^{19}$ The Ontario Health Insurance Plan (OHIP) database contains information as of 1991 on claims billed for physician and laboratory services, including endoscopic procedures. OHIP database diagnostic codes have been shown to have a high positive predictive rate $(>90 \%)^{20-23}$ and high specificity (> 85\%) $)^{24-27}$ but somewhat limited sensitivity $(35 \%-85 \%) .{ }^{24-27}$ The Registered Persons Database is a roster of OHIP beneficiaries and maintains information on age, sex, postal code and vital statistics for all Ontarians with a valid OHIP number. The ICES Physician Database provides demographic and practice-related information on all practising physicians in Ontario. The Canadian Institute for Health Information (CIHI) includes information for all patients admitted to a hospital (Discharge Abstract Database) and those receiving hospital-based procedures on an outpatient basis (Same-Day Surgery) in Ontario since Apr. 1, 1988. Finally, the CIHI National Ambulatory Care Reporting System contains data on all hospital-based and communitybased ambulatory care, including emergency department visits, for the period 1997-2012. CIHI diagnostic code sensitivity ranges from $46 \%-76 \%$, specificity is $99 \%$, positive predictive value $94 \%-98 \%$ and negative predictive value $55 \% .^{20,28}$

\section{Study cohort}

Using the OHIP database, we identified all adults over 18 years who had undergone endoscopic ultrasonography in Ontario between Jan. 1, 2003 and Dec. 31, 2011. The primary outcome was use of endoscopic ultrasonography, defined by means of procedure-specific fee codes (Appendix 1, Supplementary Table 1, available at www.cmajopen.ca/content/5/2/ E437/suppl/DC1) billed by the endoscopist who performed the procedure. Before Sept. 1, 2011, endoscopists in Ontario performing endobronchial ultrasound procedures may have also used the same fee codes. Transbronchial fine-needle aspiration is performed in over $95 \%$ of endobronchial ultrasound procedures. ${ }^{29}$ Therefore, we identified and excluded possible endobronchial ultrasound procedures using the fee codes unique to transbronchial fine-needle aspiration (E638, E677, E837) and all procedures performed by respirologists as we assumed that they had performed endobronchial ultrasonography and not endoscopic ultrasonography.

\section{Variables examined}

\section{Patient characteristics}

We collected data regarding patient age, sex, health region, comorbidity and neighbourhood income quintile at the time of the first (index) endoscopic ultrasound procedure. We determined comorbidity using the Johns Hopkins Adjusted Clinical Groups case-mix system. ${ }^{30} \mathrm{We}$ used Ontario inpatient (CIHI) and outpatient (OHIP) diagnosis codes from the year before the index date to estimate the Aggregated Diagnosis Groups using the Johns Hopkins algorithm. ${ }^{18}$ Comorbidity was categorized according to the number of Aggregated Diagnosis Groups ( $\leq 5,6-10$ or $>10)$. We determined patient socioeconomic status using median neighbourhood income quintile. The quintiles are derived from Statistics Canada census tract rankings based on the proportion of the population within each tract living below the national low-income cut-off. ${ }^{31}$

\section{Physician and institution characteristics}

We examined the health region of primary practice and main specialty of physicians who performed endoscopic ultrasound procedures. In addition, we determined whether the institution where endoscopic ultrasonography was performed qualified as an academic hospital (based on its membership in the Council of Academic Hospitals of Ontario) or as a regional cancer centre (as listed by Cancer Care Ontario). ${ }^{32}$

\section{Health regions}

We defined health regions using Ontario's Local Health Integration Networks (LHINs), geographical regions assigned by postal code that plan, manage and fund local health care by improving access and patient experience. ${ }^{33,34}$ LHINs prioritize and allocate resources according to the health care needs of the region. Ontario is divided into 14 LHINs: North West, North East, Champlain, South East, Central East, North Simcoe Muskoka, Central, Central West, Waterloo Wellington, Toronto Central, Mississauga Halton, Hamilton Niagara, South West and Erie St. Clair (Figure 1).

\section{Statistical analyses}

We determined counts of endoscopic ultrasound procedures by year. Proportions of procedures associated with 
fine-needle aspiration were computed as percentages. Medians and interquartile ranges were calculated for age. We calculated crude rates by dividing the number of endoscopic ultrasound procedures performed in a given time (numerator) by the total number of people living in the province or health region (denominator). We performed direct age and sex standardization of rates of endoscopic ultrasound procedures using the 2006 Canadian population. We conducted data and statistical analyses using SAS version 9.13 (SAS Institute). Results are presented as bar graphs or linear plots.

\section{Ethics approval}

The Research Ethics Board at Sunnybrook Hospital, Toronto, approved this study.

\section{Results}

\section{Use}

A total of 9076 endoscopic ultrasound procedures were performed in 8001 patients in Ontario between 2003 and 2011, $3066(33.8 \%)$ of which were fine-needle aspiration biopsy procedures guided by endoscopic ultrasonography. The use

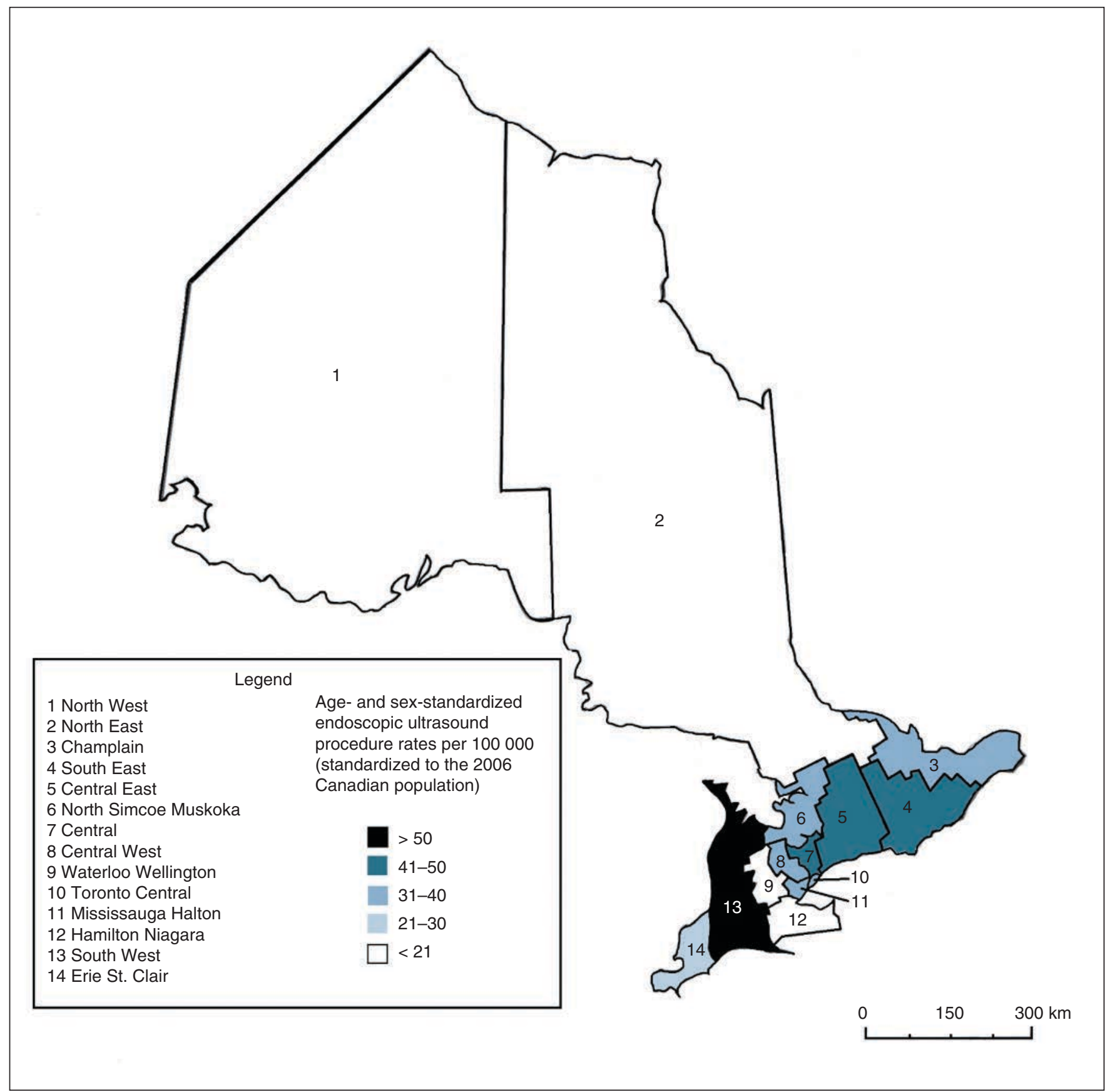

Figure 1: Age- and sex-standardized rates of use of endoscopic ultrasonography in the 14 Local Health Integration Networks in Ontario, 2011. 
of endoscopic ultrasonography increased 17 -fold from 2003 to 2011 (Figure 2). The proportion of procedures that involved fine-needle aspiration increased from $9 \%$ in 2003 to $40 \%$ in 2011.

\section{Patient characteristics}

The median age of the 8001 patients undergoing their first endoscopic ultrasound procedure was 59 years, and 3858 (48.2\%) were women. A total of 4733 patients $(59.2 \%)$ were assigned 6-10 morbidity groups (Table 1). There was an equal distribution of endoscopic ultrasound procedures among income quintile groups. Most patients (7057 [88.2\%]) lived in urban areas. There was no difference in age- and sex-standardized rates of use of endoscopic ultrasonography between urban versus rural residence or among income quintile groups over time (Appendix 2, Supplementary Figure 1, available at www.cmajopen.ca/content/5/2/ E437/suppl/DC1).

\section{Institutional and endoscopist characteristics}

Seventeen endoscopists performed endoscopic ultrasonography in Ontario during the study period. They practised in 6 of the 14 LHINs; 6 endoscopists practised in the same LHIN (Toronto Central) (Table 2). No endoscopist performing endoscopic ultrasonography practised in the 4 LHINs with the lowest rates of use of endoscopic ultrasonography (North West, North East, Waterloo Wellington and Hamilton Niagara). About 7 in 10 procedures were performed in academic or regional cancer centres. All 17 endoscopists practised in an urban area. Twelve endoscopists $(70 \%)$ were gastroenterologists, and $3(18 \%)$ were thoracic surgeons.

\section{Regional trends in use}

There was substantial regional variation in the use of endoscopic ultrasonography (Figure 1). For instance, in 2011, after adjustment for population age and sex distribution, peo-

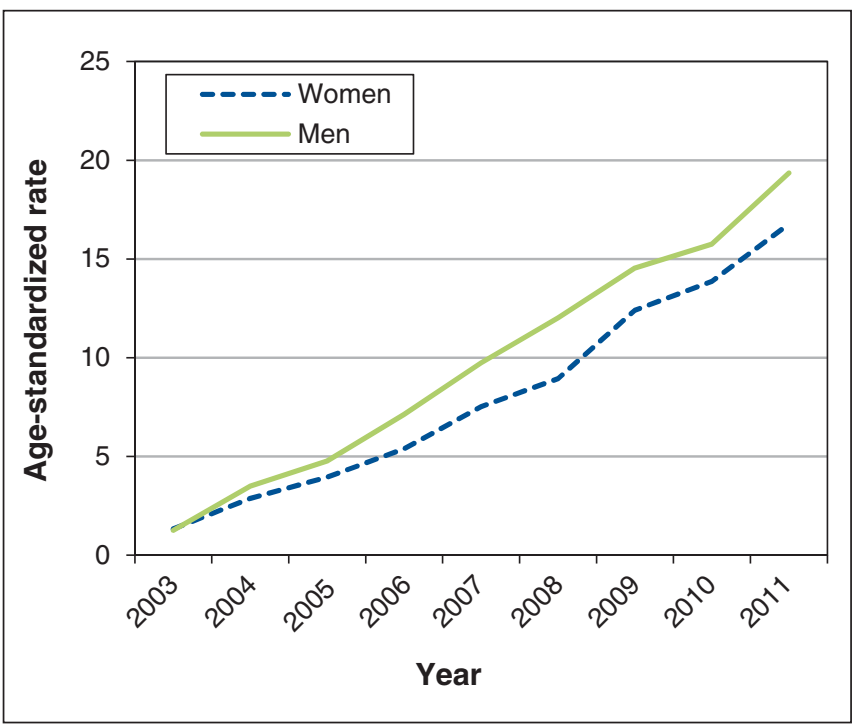

Figure 2: Age-standardized rates of use of endoscopic ultrasonography in Ontario by sex, 2003-2011. ple living in the South West LHIN were more than 4 times more likely to undergo an endoscopic ultrasound procedure than those living in the North West LHIN. Figure 3 presents the changes in the standardized rates of endoscopic ultrasound procedures over time for the 2 LHINs with the highest, lowest and median rates of use. Use increased in all 6 LHINs over time; however, there was a notable difference in the rate of uptake between the LHINs. The gap in use between the LHINs with the highest and lowest rates increased over time.

\section{Interpretation}

This population-based study shows that the number of endoscopic ultrasound procedures performed in Ontario increased 17-fold from 2003 to 2011. We also found notable differences in rates of use of the modality between health regions across Ontario. Furthermore, the gap in use of endoscopic ultrasonography between the regions with the highest and lowest rates of use increased over time.

The observed overall increase in use of endoscopic ultrasonography is consistent with previous findings in the United States ${ }^{17}$ and parallels the emergence of evidence-based indications for endoscopic ultrasound procedures as well as the rising availability of endoscopic ultrasound services. ${ }^{35}$ Little is known about regional variation in overall use of endoscopic ultrasonography at the population level, although a recent study by Schmocker and colleagues ${ }^{18}$ showed that use of the modality in patients with pancreatic cancer in the US was associated with geographical, temporal and institutional, but not clinical, factors.

\begin{tabular}{|c|c|}
\hline Characteristic & $\begin{array}{c}\text { No. (\%) of patients* } \\
n=8001\end{array}$ \\
\hline Median age (IQR), yr & $59(51-67)$ \\
\hline Female sex & $3858(48.2)$ \\
\hline Urban residence & 7057 (88.2) \\
\hline \multicolumn{2}{|l|}{ Income quintile } \\
\hline 1 (lowest) & 1539 (19.2) \\
\hline 2 & $1533(19.2)$ \\
\hline 3 & $1531(19.1)$ \\
\hline 4 & $1656(20.7)$ \\
\hline 5 (highest) & 1707 (21.3) \\
\hline Unknown & $35(0.4)$ \\
\hline \multicolumn{2}{|c|}{ No. of morbidity groups $†$} \\
\hline $0-5$ & $1924(24.0)$ \\
\hline $6-10$ & $4733(59.2)$ \\
\hline$>10$ & $1344(16.8)$ \\
\hline \multicolumn{2}{|c|}{$\begin{array}{l}\text { Note: IQR = interquartile range. } \\
\text { Except where noted otherwise. } \\
\text { †Johns Hopkins Adjusted Clinical Groups case-mix system. }\end{array}$} \\
\hline
\end{tabular}


Several factors may account for the observed regional differences in use of endoscopic ultrasonography in Ontario. For instance, the lowest rates of use were observed in health regions with no endoscopists performing endoscopic ultrasonography. On the other hand, there was notable variation in use in the health regions with multiple endoscopists performing endoscopic ultrasonography. This suggests that factors beyond endoscopist availability contribute to regional differences in use. One such factor is resource allocation. Currently in Ontario, endoscopic ultrasound programs are funded at the hospital level. Local fundraising initiatives are often required to generate the capital needed to purchase endoscopic ultrasound equipment. Academic and cancer care institutions are better suited to support such initiatives, which may explain the observation by us and others ${ }^{18}$ that most endoscopic ultrasound procedures are performed at these types of facility.

Our finding of regional differences in use of endoscopic ultrasonography in Ontario has important implications. First, the need to travel a great distance to receive an endoscopic ultrasound service is a barrier affecting accessibility in the province. This may be particularly relevant to the North East and North West LHINs, where facilitated transportation to centres with endoscopic ultrasound services or implementation of local endoscopic ultrasound centres can improve geographic access to endoscopic ultrasonography. Second, health

\begin{tabular}{|c|c|}
\hline Characteristic & No. $(\%)$ \\
\hline \multicolumn{2}{|c|}{ Institution ( $n=8001$ patients) } \\
\hline Academic centre & 3193 (39.9) \\
\hline Regional cancer centre & $2401(30.0)$ \\
\hline Other/missing data & $2407(30.1)$ \\
\hline \multicolumn{2}{|l|}{ Endoscopist $^{*}(n=17)$} \\
\hline \multicolumn{2}{|l|}{ Practising specialty } \\
\hline Gastroenterology & $12(70)$ \\
\hline Thoracic surgery & $3(18)$ \\
\hline Other† & $2(12)$ \\
\hline \multicolumn{2}{|c|}{ Health region practice location $\ddagger$} \\
\hline Toronto Central & $6(35)$ \\
\hline Central West & $2(12)$ \\
\hline Champlain & $2(12)$ \\
\hline South East & $2(12)$ \\
\hline South West & $2(12)$ \\
\hline Mississauga Halton & $1(6)$ \\
\hline Central East & $1(6)$ \\
\hline Hamilton Niagara & $1(6)$ \\
\hline \multicolumn{2}{|c|}{$\begin{array}{l}\text { “Active endoscopists during } 2011 \text { only. } \\
\text { †One endoscopist's main specialty was listed as "unknown," and } 1 \text { endoscopist's } \\
\text { main specialty was listed as "general surgery." } \\
\text { †None of the endoscopists practised in the following health regions: North West, } \\
\text { North East, Waterloo Wellington, Hamilton Niagara, Erie St. Clair, North Simcoe } \\
\text { Muskoka or Central. }\end{array}$} \\
\hline
\end{tabular}

care providers practising in regions with limited access to endoscopic ultrasonography may elect to use less accurate imaging modalities to support their medical decision-making, which can lead to compromised medical care for patients living in these regions. Third, within a province with universal health care coverage, we have identified inconsistencies in access to an important service that are not based on patient socioeconomic status but, rather, on location of residence. The Ontario government has implemented programs such as the Wait Times Strategy ${ }^{36}$ to improve efficiency of access to computed tomography and magnetic resonance imaging. This has resulted in increased availability of these modalities in previously underserviced health regions as well as for people living in less affluent neighbourhoods. ${ }^{37}$ Similar provincially based initiatives may be required to decrease the regional gap in access to endoscopic ultrasound services in Ontario.

\section{Strengths and limitations}

The main strength of this study is our ability to capture a large population-based cohort of patients encompassing almost all Ontario residents who underwent an endoscopic ultrasound procedure over a 9-year period. This allowed us to evaluate use of the modality across diverse clinical settings. Furthermore, population-based databases are less affected by referral patterns and other sources of bias observed in singleand multicentre studies. Finally, we were able to combine data from multiple sources in order to characterize patient, institutional and endoscopist factors to describe delivery of endoscopic ultrasound services at the community level.

The main limitation of our study relates to the use of Ontario health administrative data. The accuracy of OHIP billing codes for endoscopic ultrasound procedures has not

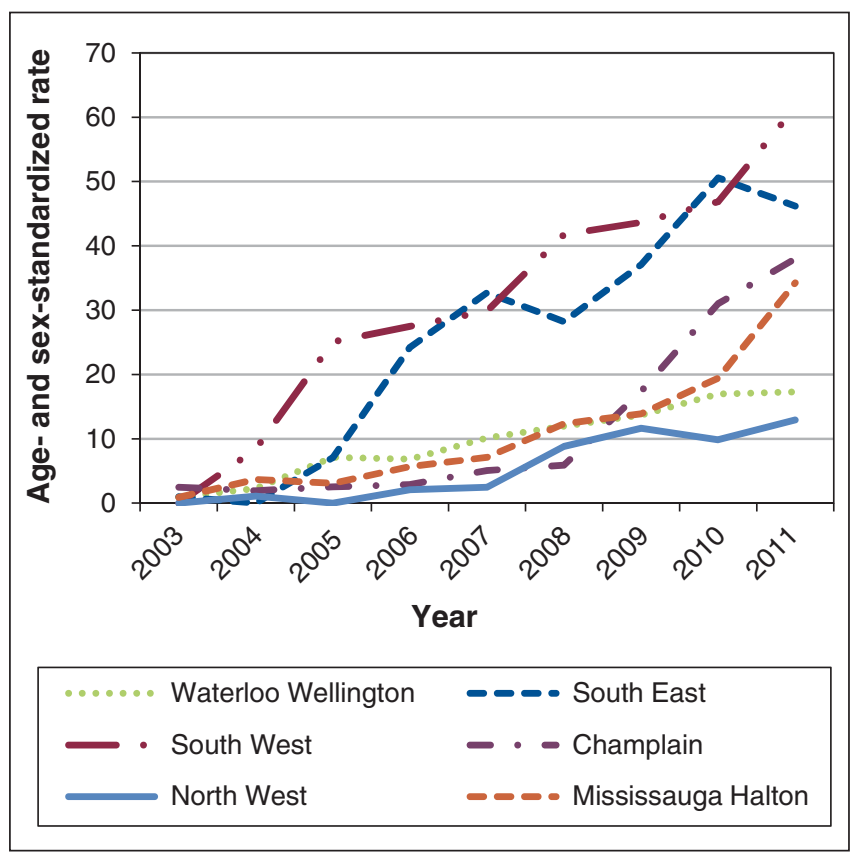

Figure 3: Age- and sex-standardized rates of use of endoscopic ultrasonography in the 2 Local Health Integration Networks with the highest, lowest and median rates of use in Ontario, 2003-2011. 
been assessed. However, OHIP billing data have been shown to be highly accurate for other procedures. ${ }^{20-27} \mathrm{We}$ attempted to maximize the specificity of the endoscopic ultrasonography codes by excluding procedures not performed by physicians in related health care specialties; however, future validation studies are needed. Second, it is possible that endoscopic ultrasound procedures performed in the earlier years of this cohort were not captured by OHIP billing codes; however, as the study period was designed to begin 2 years after codes for endoscopic ultrasonography were introduced in Ontario, we feel that this is unlikely. Third, the retrospective nature of this study entails a risk of bias. Unfortunately, large prospective population-based studies are resource intensive and may not be feasible. Fourth, patients living in health regions with low rates of endoscopic ultrasonography use may have travelled out of province to access this service, and this could not be captured in our data set. However, as 2 health regions with low rates of use (Waterloo Wellington and Hamilton Niagara) are not located near interprovincial geographic borders, we do not feel that this alone could explain our findings.

\section{Conclusion}

Although the use of endoscopic ultrasonography has increased over time in Ontario, there exist significant regional differences in rates of use. An evidence-based and provincially centralized approach to provision of endoscopic ultrasound services could help ensure that this imaging modality is available for patients whom it would benefit the most, regardless of their place of residence.

\section{References}

1. Kim E, Telford JJ. Endoscopic ultrasound advances, part 1: diagnosis. Can 7 Gastroenterol 2009;23:594-601.

2. Affolter KE, Schmidt RL, Matynia AP, et al. Needle size has only a limited effect on outcomes in EUS-guided fine needle aspiration: a systematic review and meta-analysis. Dig Dis Sci 2013;58:1026-34.

3. Cherian PT, Mohan P, Douiri A, et al. Role of endoscopic ultrasound-guided fine-needle aspiration in the diagnosis of solid pancreatic and peripancreatic lesions: Is onsite cytopathology necessary? HPB (Oxford) 2010;12:389-95.

4. Eckardt AJ, Adler A, Gomes EM, et al. Endosonographic large-bore biopsy of gastric subepithelial tumors: a prospective multicenter study. Eur 7 Gastroenterol Hepatol 2012;24:1135-44.

5. Romagnuolo J, Scott J, Hawes RH, et al. Helical CT versus EUS with fine needle aspiration for celiac nodal assessment in patients with esophageal cancer. Gastrointest Endosc 2002;55:648-54.

6. Puli SR, Reddy JB, Bechtold ML, et al. Accuracy of endoscopic ultrasound to diagnose nodal invasion by rectal cancers: a meta-analysis and systematic review. Ann Surg Oncol 2009;16:1255-65.

7. Puli SR, Reddy JB, Bechtold ML, et al. Accuracy of endoscopic ultrasound in the diagnosis of distal and celiac axis lymph node metastasis in esophageal cancer: a meta-analysis and systematic review. Dig Dis Sci 2008;53:2405-14

8. Agarwal B, Abu-Hamda E, Molke KL, et al. Endoscopic ultrasound-guided fine needle aspiration and multidetector spiral CT in the diagnosis of pancreatic cancer. Am 7 Gastroenterol 2004;99:844-50.

9. Canadian Cancer Society's Advisory Committee on Cancer Statistics. Canadian Cancer Statistics 2015. Toronto: Canadian Cancer Society; 2015. Available: https://www.cancer.ca/ /media/cancer.ca/CW/cancer\%20information/ cancer\%20101/Canadian\%20cancer\%20statistics/Canadian-Cancer-Statistics -2015-EN.pdf (accessed 2017 Mar. 20)

10. Changing patterns of esophageal cancer: adenocarcinoma on the rise. Toronto: Cancer Care Ontario; 2013. Available: https://www.cancercare.on.ca/cms/one. aspx?pageId=9819 (accessed 2017 Mar. 20).

11. Stinton LM, Shaffer EA. Epidemiology of gallbladder disease: cholelithiasis and cancer. Gut Liver 2012;6:172-87.

12. Peery AF, Dellon ES, Lund J, et al. Burden of gastrointestinal disease in the United States: 2012 update. Gastroenterology 2012;143:1179-87.
13. Dyer SM, Levison DB, Chen RY, et al. Systematic review of the impact of endoscopic ultrasound on the management of patients with esophageal cancer. Int 7 Technol Assess Health Care 2008;24:25-35.

14. Nickl NJ, Bhutani MS, Catalano M, et al. Clinical implications of endoscopic ultrasound: the American Endosonography Club Study. Gastrointest Endosc 1996;44:371-7.

15. James PD, Tsolakis AV, Zhang $M$, et al. Incremental benefit of preoperative EUS for the detection of pancreatic neuroendocrine tumors: a meta-analysis. Gastrointest Endosc 2015;81:848-56.

16. James PD, Meng ZW, Zhang M, et al. The incremental benefit of EUS for identifying unresectable disease among adults with pancreatic adenocarcinoma: a meta-analysis. PLoS One 2017;12:e0173687.

17. D'Souza SL, Holub JL, Pavic BT, et al. Multicenter evaluation of the utilization of endoscopic ultrasound. Dig Endosc 2016;28:738-43.

18. Schmocker RK, Vanness DJ, Greenberg CC, et al. Utilization of preoperative endoscopic ultrasound for pancreatic adenocarcinoma. HPB (Oxford) 2017;19: 465-72.

19. Hall S, Schulze K, Groome P, et al. Using cancer registry data for survival studies: the example of the Ontario Cancer Registry. F Clin Epidemiol 2006;59:67-76.

20. Lee DS, Stitt A, Wang X, et al. Administrative hospitalization database validation of cardiac procedure codes. Med Care 2013;51:e22-6.

21. Hussain MA, Mamdani M, Saposnik G, et al. Validation of carotid artery revascularization coding in Ontario health administrative databases. Clin Invest Med 2016;39:E73-8.

22. Jetty $\mathrm{P}$, van Walraven C. Coding accuracy of abdominal aortic aneurysm repair procedures in administrative databases - a note of caution. 7 Eval Clin Pract 2011;17:91-6.

23. Singh SM, Webster L, Calzavara A, et al. Validation of algorithms to identify invasive electrophysiology procedures using administrative data in Ontario, Canada. Med Care 2017;55:e44-50.

24. Scales DC, Guan J, Martin CM, et al. Administrative data accurately identified intensive care unit admissions in Ontario. 7 Clin Epidemiol 2006;59:802-7.

25. Widdifield J, Bernatsky S, Paterson JM, et al. Accuracy of Canadian health administrative databases in identifying patients with rheumatoid arthritis: a validation study using the medical records of rheumatologists. Arthritis Care Res (Hoboken) 2013;65:1582-91.

26. Tu K, Wang M, Young J, et al. Validity of administrative data for identifying patients who have had a stroke or transient ischemic attack using EMRALD as a reference standard. Can 7 Cardiol 2013;29:1388-94.

27. Schultz SE, Rothwell DM, Chen Z, et al. Identifying cases of congestive hear failure from administrative data: a validation study using primary care patient records. Chronic Dis Inj Can 2013;33:160-6.

28. Welk B, Loh E, Shariff SZ, et al. An administrative data algorithm to identify traumatic spinal cord injured patients: a validation study. Spinal Cord 2014;52:34-8.

29. Bugalho A, Ferreira D, Eberhardt R, et al. Diagnostic value of endobronchial and endoscopic ultrasound-guided fine needle aspiration for accessible lung cancer lesions after non-diagnostic conventional techniques: a prospective study. BMC Cancer 2013;13:130.

30. Austin PC, van Walraven C. The Mortality Risk Score and the ADG score two points-based scoring systems for the Johns Hopkins Aggregated Diagnosis Groups to predict mortality in a general adult population cohort in Ontario, Canada. Med Care 2011;49:940-7.

31. James PD, Wilkins R, Detsky AS, et al. Avoidable mortality by neighbourhood income in Canada: 25 years after the establishment of universal health insurance. 7 Epidemiol Community Health 2007;61:287-96.

32. Regional cancer programs and regional cancer center locations. Toronto: Cancer Care Ontario; 2015. Available: https://www.cancercare.on.ca/pcs/treatment/ rcchospitals (accessed 2017 Mar. 20).

33. Ontario's LHINs. Toronto: Queen's Printer for Ontario; 2014. Available: www.lhins.on.ca/ (accessed 2017 Mar. 20).

34. Coburn N, Przybysz R, Law C, et al. Utilization of CT and MRI scanning among cancer patients in Ontario, 1993-2002: ICES investigative report. Toronto: Institute of Clinical and Evaluative Sciences; 2005. Available: www. ices.on.ca/ /media/Files/Atlases-Reports/2005/Utilization-of-CT-and-MRI -scanning-among-cancer-patients/Full\%20report.ashx (accessed 2017 Mar. 20).

35. Luo LN, He LJ, Gao XY, et al. Endoscopic ultrasound for preoperative esophageal squamous cell carcinoma: a meta-analysis. PLoS One 2016;11:e158373.

36. Ontario wait times. Toronto: Ontario Ministry of Health and Long-Term Care; 2008. Available: www.health.gov.on.ca/en/public/programs/waittimes/ strategy.aspx (accessed 2017 Mar. 20).

37. Alter DA, Bell CM, Bhamani A, et al. Access to health services in Ontario: ICES atlas. 2nd ed. Toronto: Institute for Clinical Evaluative Sciences; 2006.

Affiliations: Department of Medicine and Ottawa Hospital Research Institute (James, Hegagi, Antonova), University of Ottawa, Ottawa, Ont.; Department of Medicine (Tinmouth, Yeung, Yong), University of Toronto, Toronto, Ont.; Departments of Medicine and of Community Health Sciences (Heitman), University of Calgary, Calgary, Alta.; Department of Medicine (Tinmouth, Yong), Sunnybrook Health Sci- 
ences Centre; Institute of Health Policy, Management and Evaluation (Tinmouth), University of Toronto; Cancer Care Ontario (Tinmouth); Department of Surgery (Simone), University of Toronto; Medicine Program (Yeung), The Scarborough Hospital, Toronto, Ont.

Contributors: Paul James, Jill Tinmouth, Steven Heitman, Elaine Yeung and Elaine Yong conceived and designed the study. Paul James, Jill Tinmouth, Steven Heitman and Elaine Yong collected and interpreted the data. Carmine Simone analyzed the data. Paul James, Mae Hegagi, Lilia Antonova, Jill Tinmouth, Steven Heitman, Elaine Yeung and Elaine Yong contributed to drafting the manuscript, and Paul James, Mae Hegagi and Lilia Antonova contributed to revising it. All of the authors approved the final version to be published and agreed to act as guarantors of the work.

Funding: Paul James was supported by Clinical Research Fellowship Awards from the Canadian Association of Gastroenterology, the Cana- dian Institutes of Health Research and Alberta Innovates - Health Solutions. Steven Heitman holds the N.B. Hershfield Professorship in Therapeutic Endoscopy at the Cumming School of Medicine, University of Calgary.

Disclaimer: This study was supported by the Institute for Clinical Evaluative Sciences (ICES), which is funded by an annual grant from the Ontario Ministry of Health and Long-Term Care (MOHLTC). The opinions, results and conclusions reported in this article are those of the authors and are independent from the funding sources. No endorsement by the ICES or the Ontario MOHLTC is intended or should be inferred.

Supplemental information: For reviewer comments and the original submission of this manuscript, please see www.cmajopen.ca/content $/ 5 / 2$ / E437/suppl/DC1 